\title{
VARIACIONES ANATÓMICAS EN LA FORMACIÓN, EMERGENCIA Y RECORRIDO DEL NERVIO CIÁTICO CON RELACIÓN AL MÚSCULO PIRIFORME
}

\author{
Anatomical variations in the formation, emergence and travel of the sciatic nerve in relation \\ to the piriformis muscle \\ Mondragón Yuto, Lisbeth ${ }^{1, \mathrm{a}, ~} \stackrel{\text { Е }}{\text {, Pumacayo Vargas, Milagros }}{ }^{1, \mathrm{a}}$, Montes-Oviedo, Sonia ${ }^{1, \mathrm{~b}}$ \\ 1 Escuela profesional de Medicina, Universidad Andina del Cusco, Cusco, Perú. \\ a Estudiante de Medicina \\ b Medico cirujano \\ Ð17100454f@uandina.edu.pe
}

Citar como: Mondragon, L., Pumacayo, M., Montes-Iviedo, S. (2018). Variaciones anatómicas en la formación, emergencia y recorrido del nervio
ciático con relación al músculo piriforme (carta al editor). Rev Yachay, 7(1), 503-504.

Recibido: 16-09-2018; Aceptado 07-12-2018

Señor editor

En el trabajo de Virendra B., Rakhin R., Rekha L., Prabhat . G., Subhash C. , 2013), se observó al nervio ciático con relación al músculo piriforme en treinta cadáveres (60 Extre. Inf.), obtenido en el Departamento de Anatomía del Teerthanker Mahaveer Medical College y Centro de Investigación.

Las relaciones anatómicas entre el nervio ciático y el músculo piriforme — de acuerdo con Beaton y Anson-, se clasificaron en seis tipos. La relación variable del nervio ciático se encontró que emerge por debajo del músculo piriforme en el 68,33\% de los casos; en el $31,66 \%$ de los casos el nervio ciático estaba dividido por encima de la pelvis. En el 18,33\% de los casos el componente peroneo común emergió arriba y, en el 13,33\% de los casos emergió perforando el músculo piriforme (Ibíd.). En cuarenta y un extremidades (68,33\%), el nervio ciático emergió en la región glútea debajo del musculo piriforme; es mencionado en la mayoría de los libros de texto de anatomía. En diecinueve extremidades (31,66\%) el nervio tibial y el nervio peroneo común, se separaron temprano en la pelvis y emergió por separado con relación al músculo piriforme.

De diecinueve extremidades, en ocho de ellas (13.33\%) el nervio peroneo común, perforó el músculo piriforme y el nervio tibial emergió debajo de ella. En once extremidades (18.33\%) surgió el nervio peroneo común por encima del músculo piriforme y el nervio tibial emergió debajo de ella.

El fracaso de la aproximación de la parte dorsal y ventral de los componentes conduce a una alta división del nervio ciático en la región pélvica, como se observó en el 31,66\% de casos del presente estudio y algunos otros estudios como 11,11\% (A. D. Shewale; R. R. Karambelkar; B. N. Umarji, 2013), 16,3\% (Prakash, Bhardwaj A K, Devi M N, Sridevi N S, Rao P K, Singh G, 2013).

El nervio ciático constituye la rama terminal del plexo sacro, sale de la pelvis y entra en la región glútea. El conocimiento adecuado de las variaciones del nervio ciático es útil, puesto que tiene énfasis en aplicaciones clínicas de anestesia y cirugía para que de este modo los cirujanos practiquen cirugías eficientes evitando errores.

Referencias bibliográficas

A. D. Shewale; R. R. Karambelkar; B. N. Umarji. (enero-junio de 2013). Study of Variations in the Divisions, Course and Termination of the Sciatic Nerve. Journal of Krishna Institute of Medical Sciences University, 2(1), 62-68. Recuperado el 6 de enero de 2019, de http://www.jkimsu.com/jkimsu-vol2no1/jkimsu,\%20vol\%202,\%20no\%201,\%20jan\%20\%20june\%202013,\%2062-68.pdf 
Prakash, Bhardwaj A K, Devi M N, Sridevi N S, Rao P K, Singh G. (2013). Sciatic nerve division: a cadaver study in the Indian population and review of the literature. Singapore Med Journal, 9(51), 721-723. Recuperado el 6 de enero de 2019, de http://smj.sma.org.sg/5109/5109a5.pdf

Virendra B., Rakhin R., Rekha L., Prabhat . G., Subhash C. . (2013). Estudio de la posición, forma y tamaño del foramen mental utilizando varios parámetros en mandíbulas humanas adultas secas del norte de la India. Oalib Journal, 104(3), 208-213. doi:http://dx.doi.org/10.5402/2013/961429
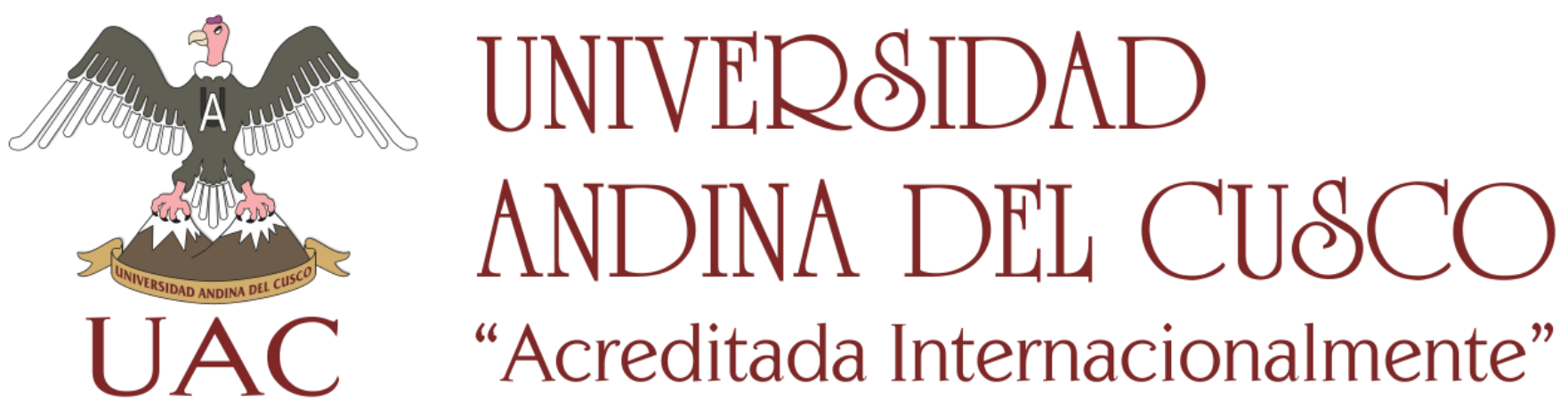